\title{
Input-current-shaper based on a modified SEPIC converter with low voltage stress
}

\author{
Petersen, Lars
}

Published in:

Proceedings of IEEE 32nd Annual Power Electronics Specialists Conference

Link to article, DOI:

10.1109/PESC.2001.954194

Publication date:

2001

Document Version

Publisher's PDF, also known as Version of record

Link back to DTU Orbit

Citation (APA):

Petersen, L. (2001). Input-current-shaper based on a modified SEPIC converter with low voltage stress. In Proceedings of IEEE 32nd Annual Power Electronics Specialists Conference (Vol. 2, pp. 666-671)

https://doi.org/10.1109/PESC.2001.954194

\section{General rights}

Copyright and moral rights for the publications made accessible in the public portal are retained by the authors and/or other copyright owners and it is a condition of accessing publications that users recognise and abide by the legal requirements associated with these rights.

- Users may download and print one copy of any publication from the public portal for the purpose of private study or research.

- You may not further distribute the material or use it for any profit-making activity or commercial gain

- You may freely distribute the URL identifying the publication in the public portal

If you believe that this document breaches copyright please contact us providing details, and we will remove access to the work immediately and investigate your claim. 


\title{
*Input-Current-Shaper Based on a Modified SEPIC Converter with Low Voltage Stress
}

\author{
Lars Petersen \\ Department of Electric Power Engineering, ELTEK \\ Technical University of Denmark, B. 325, DK-2800 Lyngby, DENMARK \\ Tel: (+45) 45253481 , Fax: (+45) 45886111 \\ e-mail: 1pe@eltek.dtu.dk
}

\begin{abstract}
The boost topology is often the designer's first choice when dealing with PFC front-ends. This topology is well documented in the literature and has obvious advantages like continuous input current and low voltage- and current-stress compared to other PFC topologies. The PFC SEPIC converter also has the advantage of the continuous input current but suffers from high voltage- and current stress. In this paper a Modified SEPIC converter is presented with reduced voltage stress, comparable to that of the boost converter. Experimental result of a $200 \mathrm{~W}$ prototype for $185-270 \mathrm{~V}$ line voltage will also be presented.
\end{abstract}

\section{INTRODUCTION}

By January 2001 the European standard, EN61000-3-2, will be a reality. The limits on the current harmonics imposed by EN61000-3-2 have been one of the driving forces in the past decade concerning research in the field of Power Factor Correction (PFC) and Input Current Shaping (ICS). For many applications, the main goal is not to achieve unity Power Factor (PF) but just to stay within the harmonic current-limits by minimum effort concerning circuit-complexity, cost and loss of efficiency. Therefore researchers have put a lot effort into developing power converters that could achieve PFC together with fast regulation of the output voltage ([1], [2]) (Single-stage topologies). The most commonly used topology for PFC, is the boost-converter. The distinct advantage of this topology is the continuous input current making EMIfiltering less of a problem compared to buck, buck-boost topologies. By using a boost-converter the output voltage has to be higher than the line peak voltage, which is not necessarily the optimal operating point for the following DC/DC-stage.

The SEPIC converters input current is continuous and the output voltage can be lower than the line peak voltage. The major drawback of the SEPIC converter is the high current and voltage stress of the components [3].

In [4] it is shown how the SEPIC-converter in Discontinuous Conduction Mode (DCM) with a simple voltage loop achieves good PF. The voltage loop bandwidth has to be low in order not to regulate on voltage fluctuations caused by the pulsating power drawn from the line.

Because of the voltage stress the use of IGBTs instead of MOSTETs are preferable. Since the switching abilities of IGBTs can be a problem concerning the efficiency, soft switching techniques are often employed ([4], [5]) further increasing the circuit complexity. In [6] the Sheppard-Taylor topology is used as a PFC converter with the ability of creating a voltage lower than the line peak voltage with continuous input current but with increased circuit complexity as a result. In [7]-[9] buck topologies are used. A way to increase the PF for the buck converters is shown in [8] and [9], where a buck-boost converter is operated in parallel with the buck converter, so that current is flowing from the line even though the output voltage is above the instantaneous line voltage.

When considering the different PFC topologies that are able to produce a voltage below the line peak voltage, the SEPIC converter seems to be an attractive alternative; mainly because of the continuous input current. In this paper a converter based on the SEPIC converter will be proposed as a PFC front-end. The voltage stress in the proposed converter is comparable with the voltage stress in the boost converter.

In section II the proposed Modified SEPIC converter will be introduced. In section III, two different operation modes will be described and in section IV the theoretical calculations of section III will be experimentally verified with two different prototypes for line voltages in the range of $185 \mathrm{Vac}-270 \mathrm{Vac}$.

\section{THE MODIFIED SEPIC CONVERTER}

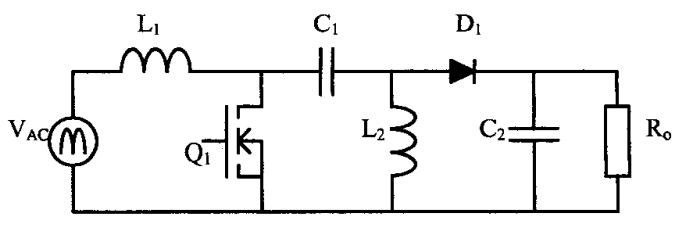

Fig. 1. Classical PFC SEPIC converter

The proposed converter is based on the classical SEPIC converter shown in Fig. 1, and compared to this converter, the proposed Modified SEPIC converter differs in two ways. The capacitor $C_{1}$ is a large bulk capacitor; a diode is placed in series with the inductor $\mathrm{L}_{2}$. The bulk capacitor serves to decouple the pulsating input power, and the diode insures that the inductor $L_{2}$ can be operated in discontinuous mode (DCM) without the capacitor $C_{1}$ being charged to above the peak line voltage.

\footnotetext{
This work is sponsored by the Danish Energy Agency under the Energy Research Program. J.nr. 1273/00-0013
} 


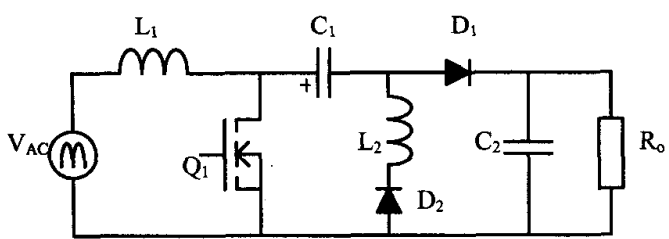

Fig. 2. Modified PFC SEPIC converter.

The inductor $\mathrm{L}_{2}$ does not necessarily have to be operated in DCM but by insuring that no current can flow in the "off" direction of $D_{2}$, the voltage $V_{C l}$ can arbitrarily be controlled by the ratio of $L_{1}$ to $L_{2}$, as long as the sum of the output voltage and $V_{C 1}$ is higher than the line peak voltage.

The drawback of adding $D_{2}$ in series with $L_{2}$, is not so much the power loss, since only part of the total power flows through $\mathrm{D}_{2}$, but the inherent galvanic isolation possibility is lost.

\section{OPERATION MODES}

The modes described in this section, are all with the Modified SEPIC converter in DCM. The DCM operation is often used in low-power applications. The advantage of this mode is small magnetics, no reverse recovery problems with the rectifiers and reduced turn-on losses in the switch. The downside is higher rms-currents and more HF noise.

\section{A. Fast regulation of the output}

When regulating the boost PFC converter, a slow outer control loop is always applied in order not to regulate the pulsating input-power. This is not necessary with the Modified SEPIC converter because that the input-power is internally decoupled by the series bulk capacitor. The output is thereby decoupled from the input, and a fast loop can be implemented.

The output power consists of two contributions; the direct transferred power from the input through $\mathrm{Ll}$ and the contribution from the series bulk capacitor, $\mathrm{C} 1$, through L2 to the output.

Because of the fast regulation loop the output power will be kept constant and the duty-cycle, d(t), will be adjusted accordingly.

$$
d(t)=\sqrt{\frac{P_{O U T}}{\frac{T_{\text {Switch }} \cdot V_{O U T} \cdot \hat{V}_{I N}^{2} \cdot \sin ^{2}(\omega t)}{2 \cdot L_{1} \cdot\left(V_{C 1}+V_{O U T}-\hat{V}_{I N} \cdot \sin (\omega t)\right)}+\frac{T_{\text {Switch }} \cdot V_{C 1}^{2}}{2 \cdot L_{2}}}}
$$

, where $T_{\text {Switch }}$ is the high-frequency switching period.
In the denominator of (1) the first fraction is related to the direct power transferred through $\mathrm{L}_{\mathrm{j}}$ and the second fraction is related to the power transferred through $\mathrm{L}_{2}$.

It is assumed that the bulk capacitor voltage, $\mathrm{V}_{\mathrm{Cl}}$, is constant during one half line period and therefore also during one switching cycle. The assumption that $\mathrm{V}_{\mathrm{Cl}}$ is constant during one half of the line period is not entirely correct. Twice the line frequency voltage-variation will be present on the capacitor $C_{1}$.

The input power to the converter is given by:

$P_{I N}=\frac{1}{N} \cdot \sum_{n=1}^{N} \frac{T_{\text {Switch }} \cdot d(n)^{2} \cdot \hat{V}_{I N}^{2} \cdot \sin ^{2}\left(\frac{n \cdot \pi}{N}\right) \cdot\left(V_{C 1}+V_{\text {OUT }}\right)}{2 \cdot L_{1} \cdot\left(V_{C 1}+V_{\text {OUT }}-\hat{V}_{I N} \cdot \sin \left(\frac{n \cdot \pi}{N}\right)\right)}$

In (2), $\mathrm{N}$ is the number of switch cycles during one half line period, and $\mathrm{n}$ is a running integer.

It has been shown in numerous papers (e.g. [2], [3] and [10]) how $V_{C 1}$ can be determined numerically. By using (1) and (2) one can determine $V_{C 1}$ as a function of the ratio $L_{1}$ to $\mathrm{L}_{2}$, the input voltage and a given output voltage. The ratio of $\mathrm{L}_{1}$ to $\mathrm{L}_{2}$ should be chosen so that the maximum voltage level applied to $C_{1}$ and $Q_{1}$ in Fig.2 is below the desired level.

In order to demonstrate the input current shaping a $200 \mathrm{~V}$ output Modified SEPIC converter will be used. The use of $500 \mathrm{~V}$ MOSFETs is desirable, so the ratio of $L_{1}$ to $L_{2}$ will be adjusted according to a maximum voltage stress on $Q_{1}$ of $450 \mathrm{~V}$. The capacitor $C_{1}$ should then be able to withstand $250 \mathrm{~V}$. With a ratio $\mathrm{L}_{1} / \mathrm{L}_{2}=1.25$, the voltage at the drain of $\mathrm{Q}_{1}$ will stay below $450 \mathrm{~V}$.

Calculating the input current waveforms for a design of a $100 \mathrm{~W}$ converter operated from $185-270 \mathrm{Vac}$, results in the waveforms shown in Fig. 3.

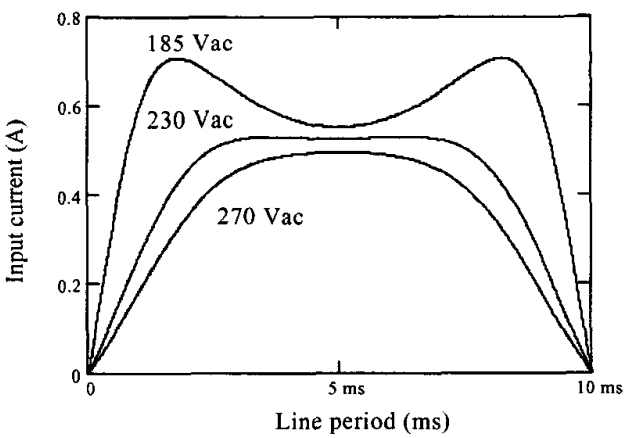

Fig. 3. Input current waveforms with line voltages of $185 \mathrm{Vac}$, $230 \mathrm{Vac}$ and $270 \mathrm{Vac}$ for the Modified SEPIC converter with fast output regulation. $\mathrm{P}_{\mathrm{OUT}}=100 \mathrm{~W}$. 


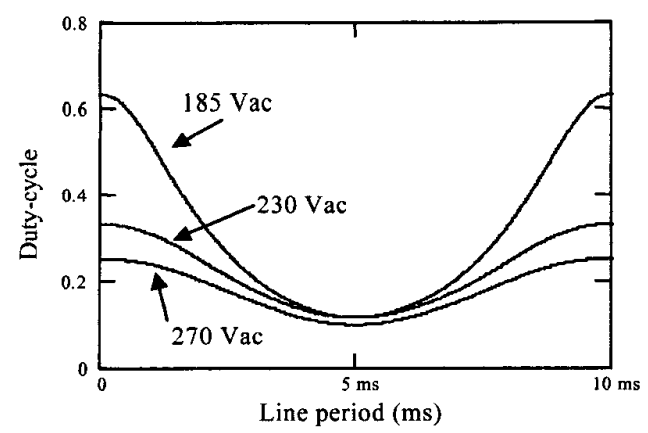

Fig. 4. Duty-cycle variations given by (1) for $185 \mathrm{Vac}$, $230 \mathrm{Vac}$ and $270 \mathrm{Vac} . \mathrm{L}_{1}=250 \mathrm{uH}$.

Figure 4 shows the time varying duty-cycle. The increasing duty-cycle when the line voltage drops from the peak value, is responsible for the current shaping.

Designing the fast outer voltage loop becomes increasingly difficult the larger the output capacity becomes. In the standard boost converter the output capacitor has to be large enough to decouple the pulsating input-power to meet the required ripple-voltage specifications. For the Modified SEPIC converter $C_{1}$ serves as the decoupling capacitor, so small polyester capacitors can be used at the output. If holdup time is required, the main energy storage is then the series bulk capacitor, $\mathrm{C} 1$.

The amount of energy stored is given by:

$E_{\text {Cap. }}=\frac{1}{2} \cdot C \cdot V_{C B}^{2}$

At low line, the voltage on $\mathrm{V}_{\mathrm{Cl}}$ is at its minimum and it is therefore in this situation, the value of the capacitor must be chosen to secure the hold-up capability. In case of a line failure the converter performs an active energy transferring from $V_{C 1}$ to the output. With the input cut-off, the converter is reduced to a buck-boost converter.

For converters with passive energy-storage (e.g. boost, buck-boost) the useable energy can be determined by:

$E_{\text {Hold }- \text { up }}=\frac{1}{2} \cdot C_{O} \cdot\left(V_{o}^{2}-V_{\min }^{2}\right)$

In (4) $C_{O}$ and $V_{O}$ is the capacitance and voltage at the output, and $V_{\min }$ is the minimum voltage that can be accepted at the output.

Using (3) and (4) a comparison of the energy storage capability can be made:
$\frac{C_{B}}{C_{O}}=\frac{V_{O}^{2}-V_{\min }^{2}}{V_{C B}^{2}}$

The Modified SEPIC converter with a maximum voltage stress of $450 \mathrm{~V}$ at $270 \mathrm{Vac}$, will have a minimum storage capacitor voltage of $100 \mathrm{~V}$ at $185 \mathrm{Vac}$. If the same size capacitor where to be used in a PFC buck-boost converter with an output voltage of $200 \mathrm{~V}$, using (5), the minimum voltage that the buck-boost converter should be able to handle is $173 \mathrm{~V}$, or a voltage drop of $13.5 \%$ of the output voltage. If the following $\mathrm{DC} / \mathrm{DC}$-stage can handle a larger voltage drop, the hold-up capabilities are better for the buckboost converter and vice versa.

\section{B. Constant peak-current control}

By using fast regulation of the output, the resulting dutycycle was seen to have a good current shaping quality. Using peak-current control with a slow voltage loop will also provide inherent high-quality input-current shaping.

When keeping the switch peak-current constant over one half line period, the duty-cycle function can be described as:

$$
d(t)=\frac{I_{r e f}}{T_{\text {Switch }} \cdot\left(\frac{\hat{V}_{I N} \cdot \sin (\omega t)}{L_{1}}+\frac{V_{C I}}{L_{2}}\right)}
$$

In (6) Iref is the demand peak-current set by the voltage loop. Since the voltage loop is slow, this reference current can be regarded as a constant, also with regard to the line period.

By inserting (6) into (1) and (2), the bulk capacitor voltage $\mathrm{V}_{\mathrm{CI}}$ can be calculated in the same manner as before.

The duty-cycle function for a $200 \mathrm{~W}, 200 \mathrm{~V}$ Modified SEPIC converter is shown in Fig. 5, and the resulting input current is shown in Fig. 6. The values of $L_{1}$ and $L_{2}$ are 220 $\mathrm{uH}$ and $160 \mathrm{uH}$.

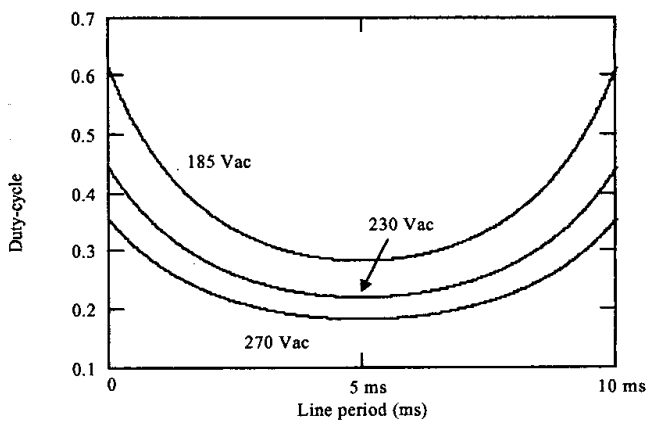

Fig. 5. The duty-cycle variation for the Modified SEPIC converter with constant peak-current control. $P_{\text {OUT }}=200 \mathrm{~W}$. 


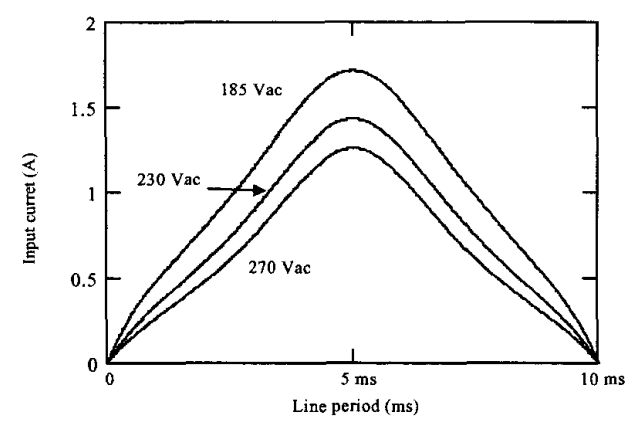

Fig. 6. Input-current waveform for the Modified SEPIC converter with constant peak-current control.

The resulting current waveforms shown in Fig. 6, is not far from being sinusoidal.

In the constant peak-current controlled converter, the energy storage can be placed at the output without creating stability problems. But in order to keep the voltage relatively constant on $\mathrm{C}_{1}$, a certain amount of capacitance should make up this capacitor.

With respect to the hold-up capability, it is not indifferent where the capacitance is located. The total energy storage to be used in case of a line failure is now, for the Modified SEPIC converter with a bulk capacitor at the output, the sum of (3) and (4). This means, that if the left side of (5) is larger than 1 , the capacitance is more useful at the output and vice versa.

\section{Alternative control strategies}

The simple voltage follower approach can also be used. The input current will exhibit the same properties as a boost converter operated in the same way.

A dedicated PFC control scheme is of course always a possibility if unity PF is the goal.

\section{EXPERIMENTAL RESULTS}

To verify the two operation modes, two prototypes have been tested. From a Power Factor point of view, the constant peak-current approach offers the most consistent high-quality current and the attention will therefore mainly be on the constant peak-current controlled converter (prototype 2).

\section{A. Prototype 1}

The first prototype with the fast-regulated output voltage was tested with a simple voltage feedback loop. A $100 \mathrm{~W}$ $200 \mathrm{~V}$ output for $185-270 \mathrm{Vac}$ input voltage were build. The following component values were used: $\mathrm{L}_{1}=250 \mathrm{uH}, \mathrm{L}_{2}=$
$200 \mathrm{uH}, \mathrm{C}_{1}=680 \mathrm{uF} / 250 \mathrm{~V}, \mathrm{C}_{2}=2.2 \mathrm{uF} / 250 \mathrm{~V}, \mathrm{Q}_{1}=\mathrm{IRF} 830$ $(500 \mathrm{~V})$. Fig. 7 shows the resulting input current for line voltages of $185 \mathrm{Vac}, 230 \mathrm{Vac}$ and $270 \mathrm{Vac}$.
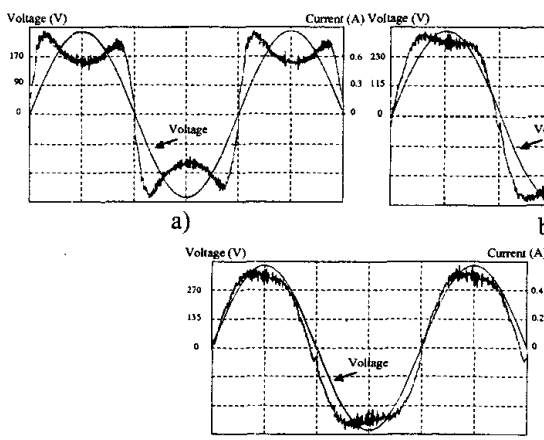

c)

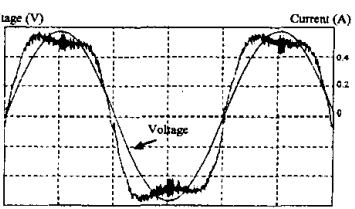

b)
Fig. 7. Input-current of the Modified SEPIC converter with fast output regulation a) $\mathrm{Vin}=185 \mathrm{Vac}, \mathrm{PF}=0.89$. b) $\mathrm{Vin}=$ 230Vac, $\mathrm{PF}=0.97$. c) $\mathrm{Vin}=270 \mathrm{Vac}, \mathrm{PF}=0.98$.
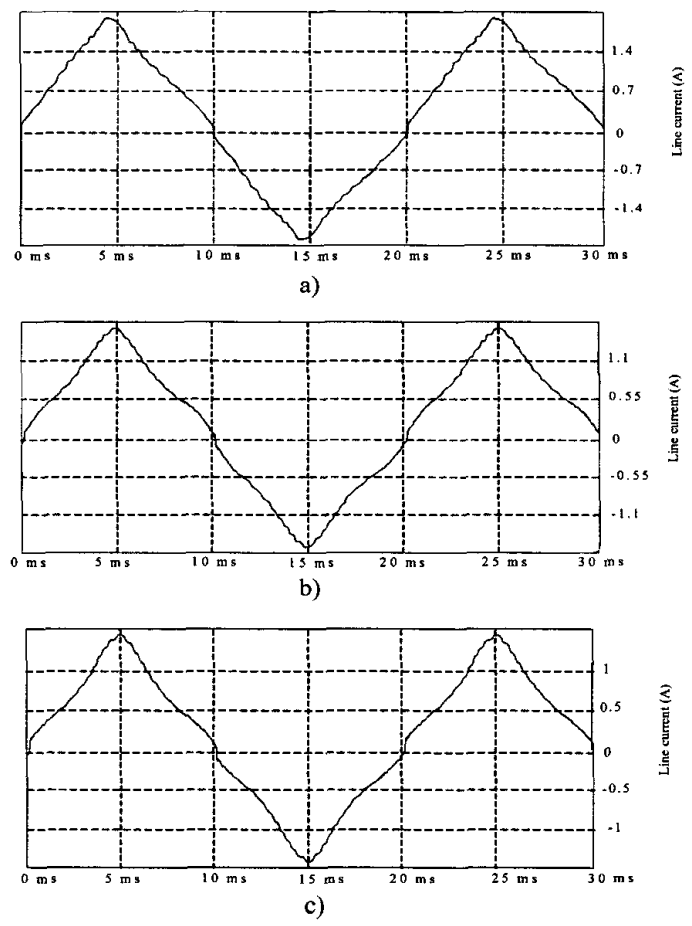

Figure 8. Input current for prototype 2 of the Modified SEPIC converter with constant peak-current control. a) Vac $=185$, PF $=0.992$. b) $\mathrm{Vac}=230, \mathrm{PF}=0.990 . \mathrm{c}) \mathrm{Vac}=270, \mathrm{PF}=0.986$

There is very god correlation with the predicted inputcurrent waveforms of Fig. 3. The asymmetry of the waveforms of Fig. 7 is caused by the $100 \mathrm{~Hz}$ voltage variation 
on the bulk capacitor $C_{1}$. Even though the PF drops rapidly when the line voltage decreases, the harmonic content of the current (not shown), is well below the limits of EN61000-3-2, both class $D$ and class $A$.

\section{B. Prototype 2}

The second prototype was realized with the constant peakcurrent control. The experimental results were taken from a $200 \mathrm{~W}, 200 \mathrm{~V}$ output for $185 \mathrm{Vac}-270 \mathrm{Vac}$. The following component values were used for this prototype: $\mathrm{L}_{1}=220 \mathrm{uH}$, $\mathrm{L}_{2}=160 \mathrm{uH}, \mathrm{C}_{1}=680 \mathrm{uF} / 250 \mathrm{~V}, \mathrm{C}_{2}=680 \mathrm{uF} / 250 \mathrm{~V}, \mathrm{Q}_{1}=$ IRFBX10N50A $(500 \mathrm{~V})$.

The input-current of the Modified SEPIC converter with the constant peak-current control is shown in Fig. 8. Again, the correlation between the predicted current waveforms of Fig. 6 and the experimental obtained is very good.

Fig. 9 shows the efficiency for the nominal line voltage of $230 \mathrm{Vac}$ as a function of the output-power, and Fig. 10 shows the efficiency as a function of the line voltage (185Vac$270 \mathrm{Vac}$ ) at $200 \mathrm{~W}$.

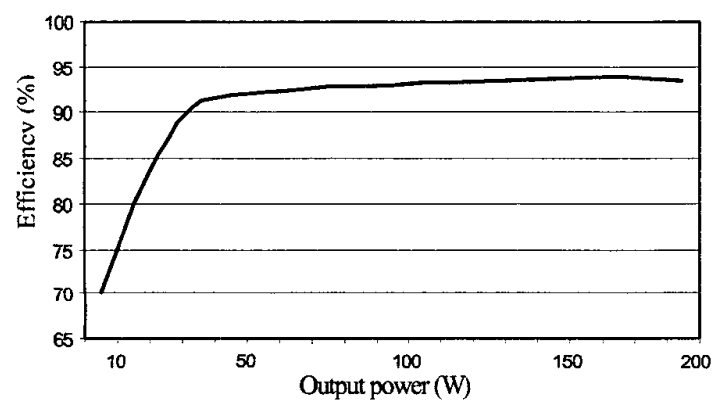

Fig.9. Efficiency as a function of output-power for $230 \mathrm{Vac}$ line voltage (prototype 2).

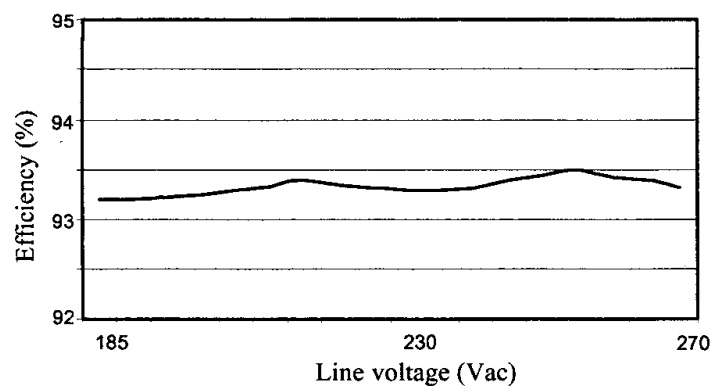

Fig. 10. Efficiency as a function of the line voltage at $P_{\text {OUT }}=200 \mathrm{~W}$ for prototype 2 .
The efficiency at maximum output power over the line voltage variation is above $93 \%$. The line variation has very little effect on the efficiency, below $0.5 \%$ percent. Compared to a boost converter, the high-line efficiency of the Modified SEPIC converter is relatively far away from what can be expected from a boost converter, but at the low line, this relation improves. Since a $400 \mathrm{VDC}$ link-voltage not necessarily is the optimal operation point for the following $\mathrm{DC} / \mathrm{DC}$ stage, the total system efficiency could be as good, or better than a standard approach with a boost converter.

\section{FUTURE WORK}

The Modified SEPIC converter is not restricted to operate in DCM, even though this paper has only dealt with this operation mode. Ongoing work shows, that CCM operation is possible using the constant peak-current control. A working $200 \mathrm{~W}$ prototype for universal mains $(90 \mathrm{Vac}-270 \mathrm{Vac})$ is being investigated and the results obtained in this work, will be presented in a future paper.

\section{CONCLUSSION}

The task of shaping the input current to comply with EN61000-3-2 can be achieved using standard DC/DC control IC's. Reducing the voltage stress to a level where the range of components is larger makes the design easier to dedicate to a specific application.

For the Modified SEPIC converter the most important pros and cons are:

Pros

- Component voltage stress comparable with boost converters

- High quality input-current shaping

- Current limiting capabilities

- Uses standard current-mode control ICs

Cons

- High current stress in the switch

- High current stress in the series bulk capacitor

- Inrush current limiting and galvanic isolation is lost (compared to the classical SEPIC)

\section{REFERENCES}

M. Madigan, R. Erickson and E. Ismail, "Integrated High Quality Rectifier-Regulators”, PESC 1992 record, pp.1044-1051.

[2] R. Redl, L. Balogh and N.O. Sokal, "A New Family of Single-Stage Isolated Power-Factor Correctors 
with Fast Regulation of the Output Voltage", PESC 1994 record, pp.1137-1144.

[3] M.M. Jovanovic, D.M.C. Tsang and F.C. Lee, "Reduction of Voltage Stress in Integrated HighQuality Rectifier-Regulators by Variable-Frequency Control", APEC 1994 record, pp.569-575.

[4] J. Sebastian, J. Uceda, J.A. Cobos, J. Arau and F. Aldana, "Improving power factor correction in distributed power supply systems using pwm and ZCS-QR SEPIC topologies", PESC 1991 record, pp. 780-791.

[5] C. Oliveiraand D. Maksimovic, "Zero-currenttransition converters for high-power-factor $\mathrm{AC} / \mathrm{DC}$ applications", APEC 1996 record, pp.159-165.
[6] C.K. Tse and M.H.L. Chow, "Single stage high power factor converter using the Sheppard-Taylor topology", PESC 1996 record, pp.1191-1197.

[7] AH. Endo, T. Yamashita and T. Sugiura, "A highpower-factor buck converter", PESC 1992 record, pp.1071-1076.

[8] A.S. Kislovski, "Internal active parallel DC powerfactor and line-current correctors", INTELEC 1996 record, pp.131-136.

[9] G. Spiazzi, "Analysis of buck converters used as power factor preregulators", PESC 1997 record, pp.564-570.

[10] L. Petersen, "Advantages of using a two-switch forward in single-stage power factor corrected power supplies", INTELLEC 2000 record, pp.325331. 